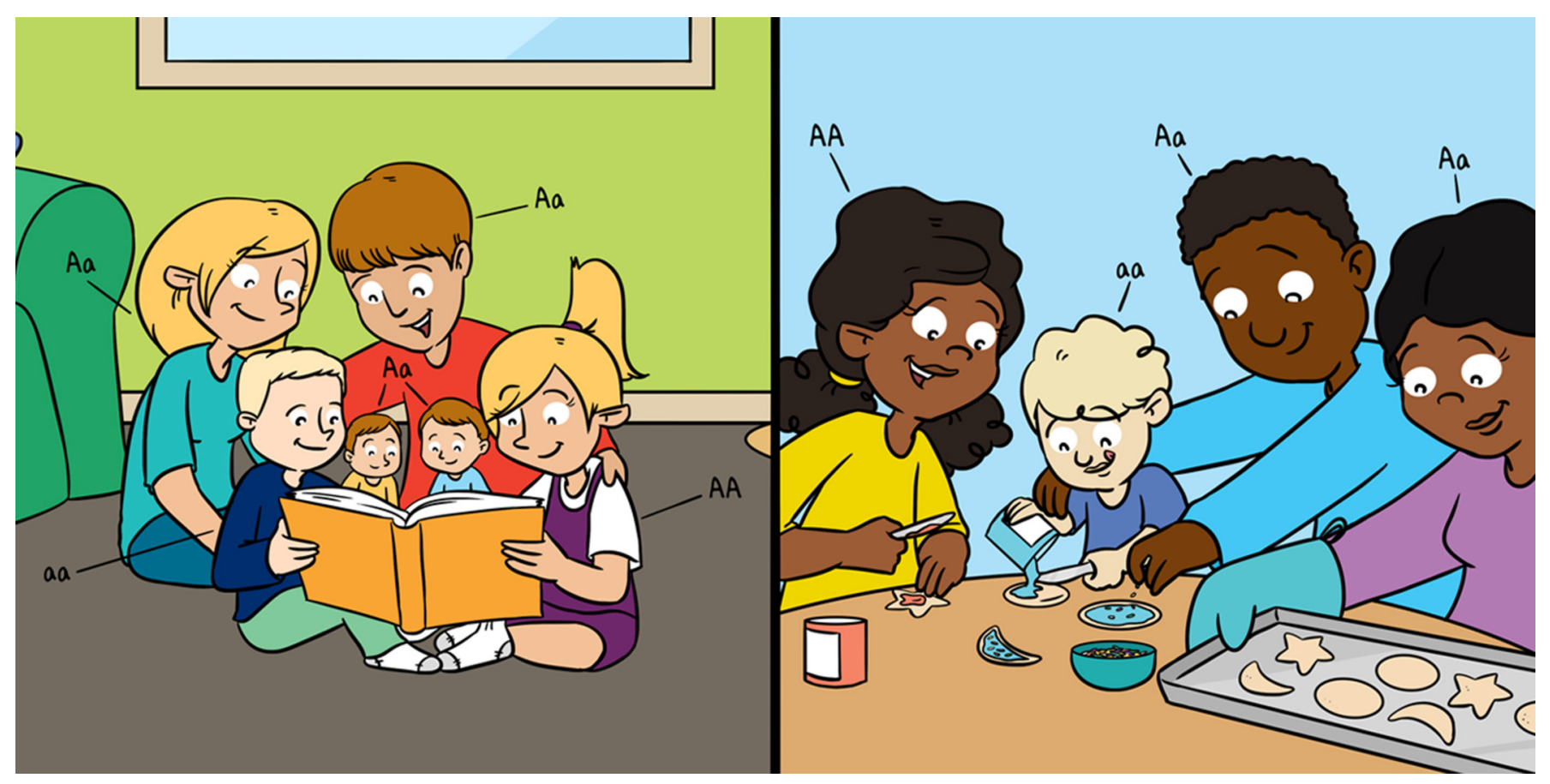

\title{
WHAT IS ALBINISM?
}

\section{Ista A. Egbeto ${ }^{1 *}$ and Jillian M. Richmond ${ }^{2 *}$}

${ }^{1}$ Tufts University School of Medicine, Boston, MA, United States

${ }^{2}$ Department of Dermatology, University of Massachusetts Medical School, Worcester, MA, United States

YOUNG REVIEWERS:

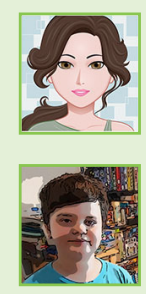

AMELIE

AGE: 9

DASHIEL

AGE: 10
Albinism is a genetic disorder that results in decreased production of a pigment called melanin in the skin, hair, and eyes, resulting in light color or no color. There are several genetic mutations that cause albinism. This condition occurs throughout the world; it affects 1 in 20,000 Americans and is more common in other parts of the world, such as in Zimbabwe, Africa, where 1 in 1,000 people have some form of albinism. Currently there is no cure for albinism, however it can be managed using sunscreen, protective clothing, eyeglasses, magnifying glasses, or eye surgery for eye abnormalities. The impact of this condition on people's lives can be devastating, so it is important to foster a positive and tolerant environment to promote the emotional and mental well-being of those who are affected.

\section{WHAT IS ALBINISM?}

Albinism is a genetic condition that decreases the production of melanin, resulting in a fair skin complexion, light eyes and hair, and increased susceptibility to various skin and eye conditions. Melanin 


\section{EUMELANIN}

The most common type of melanin-a dark pigment that is responsible for brown to black pigmentation.

\section{PHEOMELANIN}

Another type of melanin that is responsible for yellow to red hues in hair, skin, and lips.

\section{AUTOSOMAL RECESSIVE}

A genetic condition that it is passed from unaffected parents to their children. Both parents must carry at least one copy of the mutant allele and one normal copy to create a child with an autosomal recessive condition.

\section{ALLELE}

An alternative form of gene.

\section{CARRIER}

An individual that has inherited a recessive allele for a mutation but does not show any traits of the disease.

\section{MELANOCYTE}

Cells that produce melanin.

\section{TYROSINE}

The building block of melanin. The production of melanin is a multi-step process involving the conversion of tyrosine to eumelanin and pheomelanin. is the pigment that gives your skin and hair their color. It is found in the outer layer of the skin called the epidermis, in the hair, and in the eyes. Melanin helps protect your body against ultraviolet (UV) radiation from the sun and therefore helps to prevent skin damage and skin cancers. There are two main forms of melanin, called eumelanin and pheomelanin, and the relative amounts of these two types depends on a person's genetic makeup, which is inherited from their parents.

Albinism occurs as two major types: oculo-cutaneous albinism (OCA), which affects the eyes, hair, and skin, and ocular albinism (OA) which is less common and affects only the eyes [1]. Any ethnic group can be affected by albinism. It is estimated that 1 in 20,000 Americans and 1 in 17,000 Australians have some form of this condition. Albinism is more common in certain parts of the world, such as in Zimbabwe, Africa, where the prevalence is $\sim 1$ in $1,000[1,2]$.

\section{HOW DO DOCTORS DIAGNOSE ALBINISM?}

Albinism is typically diagnosed based on the observation that the skin, hair, and eyes have decreased or absent pigmentation compared to members of the same family or ethnic group. Eye examinations performed by doctors can also reveal some abnormalities, such as rapid movement of the eyes, sensitivity to bright light, or misalignment of the eyes. Genes can be tested to determine the specific type of albinism the patient has.

\section{WHAT CAUSES ALBINISM?}

Most forms of albinism are inherited in an autosomal recessive fashion, which means that it is passed directly from unaffected parents to their children (Figure 1). Because chromosomes are paired, all genes on non-sex (autosomal) chromosomes occur in two copies, called alleles. Both parents must have a mutation (a change in the DNA sequence) in one allele of a gene that causes albinism, but they also have a normal allele. People with one mutated allele for albinism, called carriers, do not have symptoms-two copies of the mutated gene (one passed on from each parent) are necessary to cause symptoms. This is why we call the albinism trait recessive, and it explains why we see more albinism within certain ethnic or national groups, and why it is less visible in other populations.

Many of the genes involved in normal pigmentation and albinism play a role in the creation or secretion of melanin. To understand how these genes can cause albinism, let us review how the products of these genes, which are proteins, help melanin-producing cells (called melanocytes) make pigment (Figure 2A). Enzymes are a special type of protein that help to make chemical reactions happen. Enzymes are responsible for changing the starting material, called tyrosine, into 
Figure 1

How is an

autosomal recessive condition like albinism passed from parents to children? In this figure, both parents are carriers of a mutation in one copy (allele) of a gene that causes albinism (represented by a lowercase a), but they also have one normal allele (uppercase A). These parents have a $25 \%$ chance of having a child with albinism (the light-skinned child), a $50 \%$ chance of having children that carry the mutated allele but are not affected, and a 25\% chance of having a child that is unaffected and does not carry the mutation.

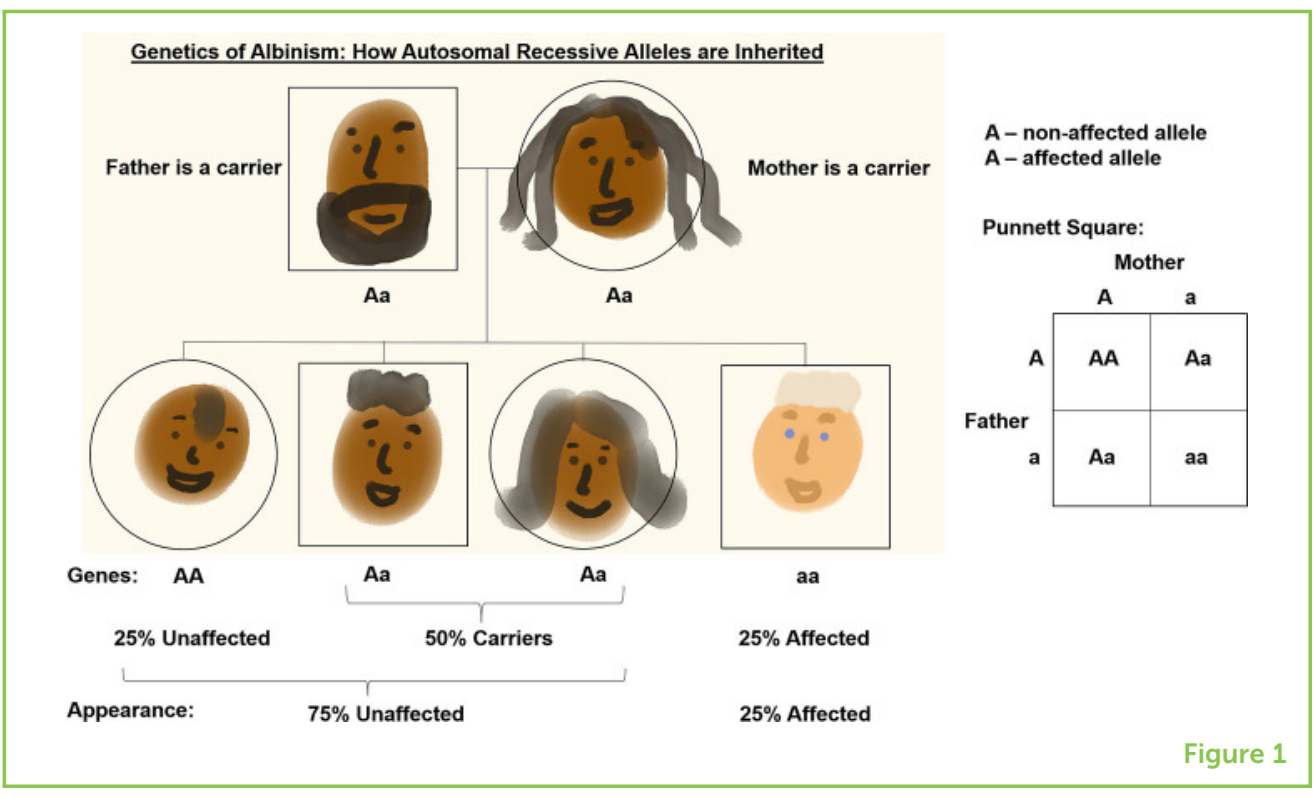

melanin. The way that the enzymes change the tyrosine is what causes the formation of eumelanin vs. pheomelanin. When one of these enzymes has a mutation, it may no longer be able to function properly, thereby impacting the melanocyte's ability to make the different types of melanin.

In normal pigmentation, the ratio of eumelanin (brown-black pigment) to pheomelanin (yellow-red pigment) is what causes differences in skin color. In albinism, melanocytes are no longer able to make eumelanin at the proper levels, resulting in formation of more or only pheomelanin (Figure 2B). There are seven types of OCA caused by different genes [3]. OCA can range in severity from complete lack of pigmentation in the skin, hair, and eyes with OCA type 1A, to light brown pigmentation in OCA type 2 , or reddish-brown pigmentation in OCA type 3 [2].

\section{HOW DOES ALBINISM AFFECT PEOPLE WHO HAVE IT?}

Individuals with albinism often experience eye problems. Most individuals with albinism have light-colored eyes, which means that they do not have the same protection from the sun's UV radiation as do people with brown or hazel eyes. This means that the eyes of individuals with albinism are easily damaged by UV radiation from the sun. They often experience premature glaucoma, general vision issues, and potential blindness. Albinism can also impair vision, resulting in nearsightedness, farsightedness, or astigmatism, which is blurry vision due to an uneven cornea.

Individuals with albinism are at a higher risk of developing skin cancers and sunburns due to increased sensitivity to the sun. The more damage caused by UV radiation, the higher the chance of getting skin cancer. 


\section{Figure 2}

There are two types of melanin. Eumelanin has a brown to black color while pheomelanin is a yellow to red. Our skin and hair color are determined by the relative amounts of the two types of melanin.

(A) On the left side, the melanocyte can make both eumelanin and pheomelanin, resulting in normal skin pigmentation. On the right side, the melanocyte can only make pheomelanin, resulting in the light-colored skin seen in albinism. This is due to a mutation that disrupts the enzyme responsible for making melanin (green circle on the left, red circle on the right). The melanin is taken up by neighboring skin cells, which gives them color and helps protect them from UV damage. (B)

The ratio of eumelanin to pheomelanin affects skin tone. The total amount of melanin (pheomelanin + eumelanin) is roughly the same across all skin types and tones.
A

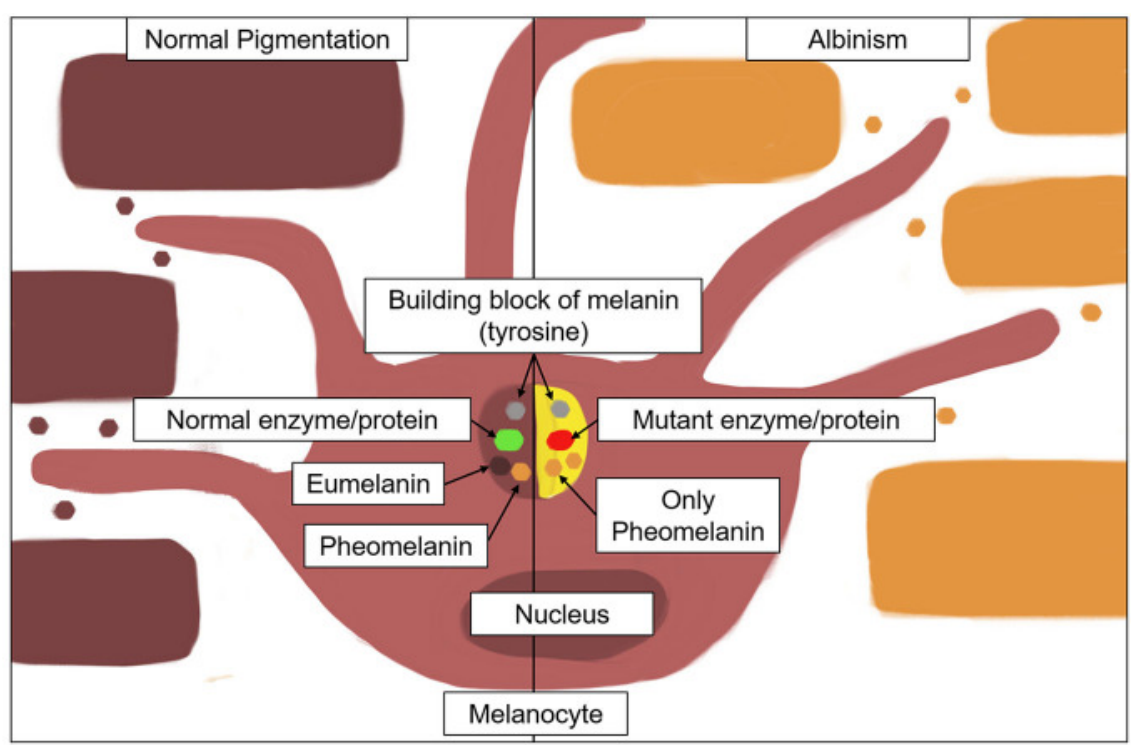

B

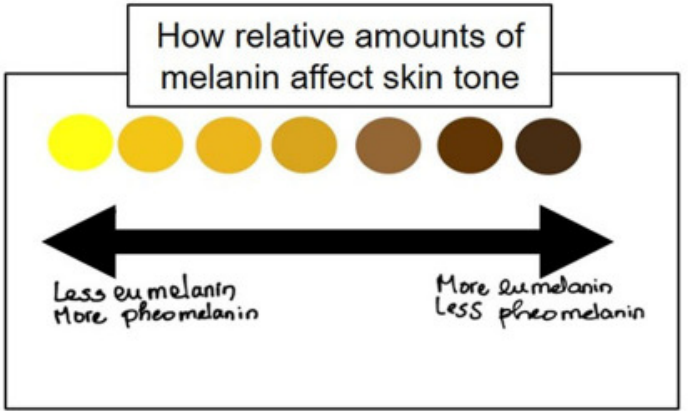

Figure 2

UV radiation contributes to the formation of skin cancer by generating substances called free radicals, which cause DNA damage in the skin. Eumelanin usually protects against UV-induced DNA damage by taking up free radicals. Pheomelanin actually causes the creation of more free radicals. Therefore, the development of skin cancer in individuals with albinism is due to both reduced protection against sun damage and the increased production of free radicals [4].

Different types of albinism come with different risks of developing skin damage and skin cancers. For example, skin cancers are a leading cause of death in certain ethnic groups, such as African albinos. Skin cancers can be prevented by protecting the skin with sunscreen and clothing and by early skin checks [5]. Skin cancers that are detected at a later stage are more difficult to treat, which is why prevention of sun damage and skin checks are so important.

\section{HOW DO DOCTORS HELP KIDS WITH ALBINISM?}

One way that doctors help kids with albinism is by encouraging protection of the skin from the sun. Some strategies to protect the 
skin from the sun's UV radiation include avoiding direct or prolonged exposure to sunlight, wearing a wide-brimmed hat, sunglasses, and high SPF (SPF 30+, applied every 2 h) sunscreen, avoiding tanning beds, and avoiding medications that cause sun sensitivity. It is crucial that doctors closely monitor children with albinism so that they can detect skin cancers early if they occur [1].

Doctors can also help kids with albinism by treating eye abnormalities. Kids with albinism should have an eye examination by the age of 4 months. Within their first 2 years, eye exams are recommended every 3-4 months, which is reduced to every 6 months between ages 2 and 4 and to once a year by the age of 5 . The frequency is further reduced to 2-3 years by the age of 18-20 [2]. Eyesight problems are treated with glasses or contact lenses to improve vision [6]. Bifocals or hand-held magnifiers can also be useful. Individuals with eye misalignments may benefit from eye muscle surgery, which helps to align the eyes properly. Surgery may have to be performed multiple times to completely fix the eye alignment.

There is no real cure for albinism, however one study investigated the use of a drug that helps to break down tyrosine in children with OCA type 1B. Children treated with the drug showed an increase in pigmentation of the hair and skin; however, vision problems were not significantly improved [7] and there were a number of unpleasant side effects. So, this drug may not work for many people, because successful treatment of vision problems is important for patients with albinism.

\section{WHAT IS LIFE LIKE FOR KIDS WITH ALBINISM?}

Children with albinism may experience a great deal of bullying due to their physical appearance [2]. This bullying can easily lead to strong feelings of being unattractive or feeling left out. To help children with albinism at school, parents, students, and teachers should work together to create individualized educational plans including the use of larger print size, preferential classroom seating, and computers for students with impaired vision. Participation in a peer support group can also help kids with albinism to improve their emotional health. It is important for everyone to realize that albinism is an important part of who these children are. Even though their skin color is different, and they might need some extra support in the classroom, these children are just like everyone else. Children with albinism have a normal range of intelligence, develop normally, and have a normal life expectancy. We should all do our part to help children with albinism to feel like they fit in. Now that you have a better understanding of what albinism is, why it occurs, and its social implications, you can share this knowledge with your family, friends, and classmates so that everyone can contribute to making life better for kids with albinism! 
More resources can be found through the National Organization for Albinism and Hypopigmentation (NOAH) website at www.albinism.org.

\section{REFERENCES}

1. Federico, J. R., and Krishnamurthy, K. 2021. "Albinism," in StatPearls (Treasure Island, FL: StatPearls Publishing). Available online at: https: //www.ncbi.nlm. nih.gov/pubmed/30085560

2. Summers, C. G. 2009. Albinism: classification, clinical characteristics, and recent findings. Optom. Vis. Sci. 86:659-62. doi: 10.1097/OPX.0b013e3181a5254c

3. Summers, C. G., Hand, J. L., Levy, M. L., and Corona, R. 2017. Oculocutaneous Albinism. Available online at: https : / / www . uptodate.com/contents / oculocutaneous-albinism

4. de Vijlder, H. C., de Vijlder, J. J. M., and Neumann, H. A. M. 2013. Oculocutaneous albinism and skin cancer risk: Letter to the Editor. J. Eur. Acad. Dermatol. Venereol. 27:e433-4. doi: 10.1111/j.1468-3083.2012.04633.x

5. Opara, K. O., and Jiburum, B. C. 2010. Skin cancers in albinos in a teaching Hospital in eastern Nigeria-presentation and challenges of care. World J. Surg. Oncol. 8:73. doi: 10.1186/1477-7819-8-73

6. Anderson, J., Lavoie, J., Merrill, K., King, R. A., and Summers, C. G. 2004. Efficacy of spectacles in persons with albinism. J. AAPOS 8:515-20. doi: 10.1016/ j.jaapos.2004.08.008

7. Adams, D. R., Menezes, S., Jauregui, R., Valivullah, Z. M., Power, B., Abraham, M., et al. 2019. One-year pilot study on the effects of nitisinone on melanin in patients with OCA-1B. JCI Insight 4:e124387. doi: 10.1172/jci.insight.124387

SUBMITTED: 06 June 2020; ACCEPTED: 19 February 2021; PUBLISHED ONLINE: 23 April 2021.

EDITED BY: Valeria Costantino, University of Naples Federico II, Italy

CITATION: Egbeto IA and Richmond JM (2021) What Is Albinism? Front. Young Minds 9:570230. doi: 10.3389/frym.2021.570230

CONFLICT OF INTEREST: The authors declare that the research was conducted in the absence of any commercial or financial relationships that could be construed as a potential conflict of interest.

COPYRIGHT (C) 2021 Egbeto and Richmond. This is an open-access article distributed under the terms of the Creative Commons Attribution License (CC BY). The use, distribution or reproduction in other forums is permitted, provided the original author(s) and the copyright owner(s) are credited and that the original publication in this journal is cited, in accordance with accepted academic practice. No use, distribution or reproduction is permitted which does not comply with these terms. 

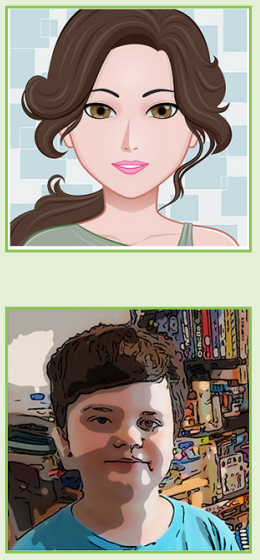

\section{YOUNG REVIEWERS}

\section{AMELIE, AGE: 12}

I have been participating in Frontiers for Young Minds for the past 3 years. Reviewing papers is one of my passions as well as reading, painting, and practicing judo. Through reading these scientific papers, I have learnt a lot about health and disease. I love to travel and my favorite animal is the pangolin.

\section{DASHIEL, AGE: 10}

$\mathrm{Hi}$ there! My name is Dashiel and I am 10 years old. My favorite sciences are biology and zoology. My hobbies include video gaming (my favorite games to play are Fortnite and Animal Crossing New Horizons), birding, and reading. I also play the Euphonium at school.

\section{AUTHORS}
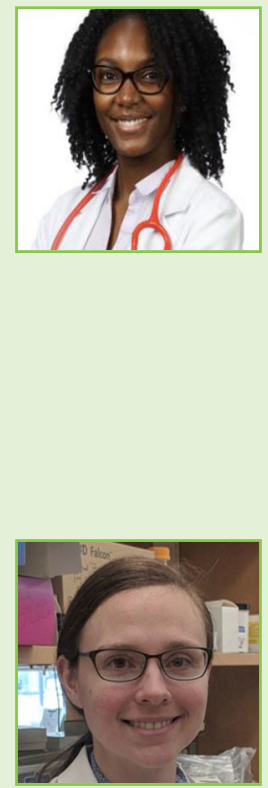

\section{ISTA A. EGBETO}

Ista Egbeto is a medical student at Tufts University School of Medicine aspiring to become a dermatologist. Prior to medical school, she attended Stony Brook University where she earned her Bachelor of Science in Cell Biology with a minor in Business Management. Ista then worked as a high school science teacher at St. Timothy's School in Stevenson, MD for 4 years and served as the Chair of the science department. She has experience in medical research in oncology. She is currently working in Dr. Richmond's lab at the University of Massachusetts Medical School as a summer fellow studying pigmentary disorders. She enjoys teaching, jewelry making, and cooking. *ista.egbeto@tufts.edu

\section{JILLIAN M. RICHMOND}

Jillian is an Assistant Professor of Dermatology at the University of Massachusetts Medical School. She earned her B.S. in Molecular and Cellular Biology from Johns Hopkins University and her Ph.D. in Immunology and Pathology from Boston University School of Medicine. Her laboratory studies the role of the immune system in skin diseases. Jillian is passionate about teaching and mentoring students in the classroom and the laboratory and discovering new treatments for patients through her research. She enjoys spending time with her kids, baking, and gardening. *jillian.richmond@umassmed.edu 